\title{
Resumen / Funcionalidad actual del séptimo arte
}

El consumo cultural nos hace comprender la arquitectura global de las sociedades: homogéneas en muchos aspectos y en otros muy desiguales y fragmentadas. Los mecanismos de la economía globalizada están llevando también a la globalización de hábitos y costumbres de la población mundial. Este aspecto del fenómeno tiene múltiples manifestaciones entre las que puede destacarse la unidimensionalidad del consumo cultural. Así, cada día los habitantes de distintas ciudades del planeta consumen al mismo tiempo los mismos productos de la industria cultural en contextos distintos conformando la sociedad del espectáculo. ¿Tiene hoy el cine una funcionalidad determinada? ¿Es manifiesta esa funcionalidad u oculta?

\section{Palabras clave}

Espectáculo - ficción - films - funcional - ilusión - industria cinematográfica - industria cultural - no ficción - popular - sobremodernidad - unidimensionalidad - verosímil.

\section{Summary / Present functionalism in the seventh art}

Cultural consumption makes us understand the global architecture of societies -homogeneous in some aspects and very unequal and fragmented in others. The mechanisms of the globalized economy are leading into the globalization of habits and customs of the world population. This aspect of the phenomenon has multiple signs, among which the unidimensionality of cultural consumption can be highlighted. Thus, every day the inhabitants of different cities in the world would consume at the same time the same products originated in the cultural industry in different contexts, constituting the show business society. Has cinema a determined functionalism today? Is this functionalism manifested or hidden?

\section{Key words}

Cinematographic industry - credible - cultural industry - fiction - films -functional - illusion - non fiction overmodernity - popular - show business - unidimensionality.

\section{Resumo / Funcionalidade atual da sétima arte}

O consumo cultural faz entender a arquitetura global das sociedades: homogêneas em muitos aspectos e em outros bem desiguais e fragmentadas. Os mecanismos da economia globalizada estão levando também à globalização de hábitos e costumes da população mundial. Este aspecto do fenômeno tem múltiplos manifestações, se destacam a unidimensionalidade do consumo cultural. Assim, cada dia os habitantes de distintas cidades do planeta consumem ao mesmo tempo os mesmos produtos da indústria cultural em contextos diferentes conformando a sociedade do espetáculo. ¿Tem hoje o cinema uma funcionalidade determinada? ¿É manifesta essa funcionalidade ou oculta?

\section{Palavras chave}

Espetáculo - ficção - filmes - funcional - ilusão - indústria cinematográfica - indústria cultural - não ficção - popular - sobre modernidade - unidimensionalidade - verosímil. 
"Si tuviera que elegir una inscripción funeraria para la tumba de estas dos personas, sé muy bien qué escribiría: "Ni contigo, ni sin ti". Pero nadie me pedirá mi opinión", sentencia la voz en off sobre el final del film La mujer de la próxima puerta de François Truffaut estrenada en 1981. Este fragmento de un monólogo de la película resume, en pocas palabras, uno de los retratos cinematográficos más complejos de una de las más complejas relaciones de pareja entre un hombre y una mujer que se han llevado a la pantalla grande.

El término complejidad es la oposición de lo que sucede en la gran mayoría de las producciones cinematográficas que se globalizan, que se proyectan al mismo tiempo en la misma oscuridad de las salas pero de diferentes culturas. Historias y personajes de una sola dimensión interpretativa, filmes efectictas con una clara misión comercial predefinida en un escritorio, producciones que siguen objetivos de consumo y que se integran como piezas de un rompecabezas a esa sociedad del espectáculo que describió Guy Debord hacia fines de la década de 1960.

Industria y comercio. Esto es el cine además de arte y espectáculo. Quien defina el cine como arte narrativo basada en la reproducción gráfica del movimiento no hace más que fijarse en un fragmento del complicado escenario. Quien añada que el cine es una técnica de difusión y medio de información habrá agregado mucho pero sigue siendo parcial. Además ser arte, espectáculo, vehículo ideológico, fábrica de mitos, instrumento de conocimiento, documento histórico de la época y la sociedad en que nace, el cine es una industria y la película una mercancía que proporciona ingresos a su productor, a su distribuidor y a su exhibidor.

Una cita de Lukács, utilizada por Debord en el prólogo del segundo capítulo del libro La Sociedad del Espectáculo, nos permitirá seguir adelante: "La mercancía no puede ser comprendida en su esencia auténtica sino como categoría universal del ser social total. Sólo en este contexto la reificación surgida de la relación mercantil adquiere una significación decisiva, tanto para la evolución objetiva de la sociedad como para la actitud de los hombres hacia ella, para la sumisión de su conciencia a las formas en que esa reificación se expresa. Aumenta esta sumisión el hecho de que cuanto más aumentan la racionalización y mecanización del proceso de trabajo, más pierde la actividad del trabajador su carácter de actividad, para convertirse en actitud contemplativa." (Debord, 1995: 51).

Visto como producto de la economía y la industria cultural, el cine participa activamente con su provisión de contenido regular e inacabable de la sociedad del espectáculo. El cine, a su vez, es un fenómeno exclusivamente urbano (no hay cines en ciudades con menos de 35 mil habitantes en la Argentina) donde el espectador espera ser ilustrado o emocionado y lucha por conseguir los frutos que la maquinaria de esta industria le entrega. Después de todo ha pagado una entrada para sentir los efectos que alguien ha creado. Además como el medio del cine es tecnológico el espectador está más dispuesto a aceptar su papel de recipiente de sensaciones.

"La alienación del espectador en beneficio del objeto contemplado (que es el resultado de su propia actividad inconsciente) se expresa en una paradoja: cuanto más contempla, menos vive, cuanto más acepta reconocerse en las imágenes dominantes de necesidad, menos comprende su propia existencia y sus propios deseos." (Debord 1995: 54).

Esta sociedad del espectáculo consume el mundo de la mercancía que se muestra así tal como es y que determina el distanciamiento de los hombres entre sí y respecto de su producto global.

\section{Consumo unidimensional}

Entendemos que en esta época de sobremodernidad tenemos un conjunto de ideas y situaciones interrelacionadas: modernización, racionalización, progreso, consumo y una visión implícita de la perfectibilidad gradual de la sociedad que se debían conseguir a través de una planificación racional y una reforma social. Sin embargo, no todo ocurre como se había planeado. Se ha invocado el concepto de posmodernidad para indicar que los límites de la modernidad ya se han alcanzado. Se ha argumentado que las promesas de la modernidad (relacionadas con la liberación del hombre en todas sus dimensiones) ya no se consideran factibles. Esas grandes esperanzas, asociadas a las formas globalizadoras y totalizadoras de la teoría social han quedado empequeñecidas. Además hay algo que se ha modificado notoriamente: desde el punto de vista del consumo de industria cultural, es la percepción. El modo actual de consumo estético está invadido por variables muchas veces prestadas o importadas por la globalización cultural.

Estos cambios en la percepción son la consecuencia de la lógica cultural de un capitalismo tardío. Ha existido una transformación fundamental en la estructura de las sociedades posmodernas la cual ha provocado cambios culturales. En sintonía con las ideas de Debord, podemos decir que estamos seducidos por el mundo hiper-real y posmoderno de imágenes que flotan en pantallas detrás de la cuales nunca hay nada. El valor derivado de su paliación ha sido totalmente eclipsado por el valor de intercambio. Las imágenes al principio reflejaban la realidad, luego la enmascaraban y finalmente señalan su ausencia. "Sin duda alguna nuestra época prefiere la imagen al objeto, la copia al original, la representación a la realidad, la apariencia a la forma de ser", señala Debord citando un escrito de Feuerbach del siglo XIX (Debord, 1995: 3). Así, por medio del bombardeo progresivo y uniforme de la información se anulan las diferencias de contenido. Lo único que queda es el espectáculo sin significado. En un universo poblado de imágenes, la crítica racional es sustituida por el éxtasis de la comunicación, un estado caracterizado por la seducción banal. 
Aún desprestigiados algunos textos del pensador contemporáneo Marc Auge pueden ayudar a encontrar un camino para seguir este pensamiento. Las cadenas internacionales de exhibición, donde se consume al menos el 75 por ciento del cine mundial, son verdaderos "no lugares" (Auge, 1992) desde la mirada antropológica que ofrece el concepto. Son espacios sin interacción social, de transición, de consumo, de escasa o nula identificación individual aunque se esfuerzan por alcanzar una identificación colectiva a la vez que tienen una carga comunicacional orientada hacia una funcionalidad específica del espacio. Auge caracteriza a la sobremodernidad con tres figuras del exceso: superabundancia de acontecimientos, superabundancia espacial y la individualización de las referencias (Auge, 1992:46). Es en este marco de acontecimientos en el que se inserta el consumo de cine actual.

La nueva configuración del consumo cinematográfico ha transformado a los productos del llamado séptimo arte en piezas de un material descartable. Ni los grandes festivales de cine logran hoy salvar a muchos films de la condena a ser desechados como el envoltorio de una golosina.

La mayoría de los críticos de cine señalan que los guiones, las historias y el perfil de los personas de los productos standarizados de la industria cinematográfica son la antítesis de la complejidad. Son de lectura rápida, de única interpretación y poseen un alto grado de predicción sobre la resolución de las historias. Los espectadores retienen con la observación regular en la sala oscura elementos propios de una sociedad del espectáculo transformando el consumo cultural en una práctica acrítica, de una sola dimensión, ligada exclusivamente al entretenimiento.

En palabras de Debord, "El espectáculo es la otra cara del dinero: el equivalente general abstracto de todas las mercancías. Pero si el dinero ha dominado la sociedad como representación de la equivalencia central, es decir, del carácter intercambiable de bienes múltiples cuyo uso seguía siendo incomparable, el espectáculo es su complemento moderno desarrollado donde la totalidad del mundo mercantil aparece en bloque (...). El espectáculo es el dinero que solamente se contempla porque en él la totalidad del uso ya se ha intercambiado con la totalidad de la representación abstracta" (Debord, 1995: 49).

Esa representación que es el cine, tiene actualmente una forma particular de consumo: es unidimensional. Carece de complejidades interpretativas y estéticas y se lo asocia a funciones otorgadas arbitrariamente al cine como entretenimiento, reflexión o incluso espacio de catarsis.

\section{Funcionalidad del cine actual}

Para el Renacimiento, el estudio de las formas de representación permite intuir el modo de percepción particular de una época; en ese sentido, el cine expresa las modalidades perceptivas de la modernidad y de su apertura al mundo. Desde este punto de vista, la experiencia sensorial del hombre inmerso en la multitud es la progenitora inmediata de la representación cinematográfica. El hombre recorre hasta el cansancio las calles ciudadanas, agredido a cada paso por una horda de seducciones y estímulos, sin poseer una visión orientada capaz de componer en una unidad orgánica y jerárquica los elementos del cosmos. Los hombres, los objetos, la naturaleza, se presentan como fotogramas en rápida fuga que el sujeto trata de capturar luchando contra su imparable fugacidad.

El cine se ha constituido en la matriz fundacional de todos los lenguajes audiovisuales que se han desarrollado a lo largo del siglo $X X$ y en lo que le compete al siglo XXI, tanto los que han surgido sobre soporte electrónico como sobre soporte informático. Todos los medios derivados del cine despliegan y muestran en una pantalla formas visuales que evolucionan sobre un eje temporal, exactamente como ocurre en la mayoría de las películas.

Pero estas nuevas manifestaciones tecnológicas y sofisticadas de la cultura de la imagen han reestructurado profundamente las industrias audiovisuales, sus métodos de trabajo, sus mercados y sus formas de consumo, que incluso han señalado la próxima muerte del cine. Esto no sucede, ya que nuevos soportes tecnológicos de reproducción y grabación de imágenes audiovisuales le han dado un impulso rejuvenecedor a éste ampliando sus posibilidades de captación de la realidad. Se ha renovado así el mito de la relación del cine con la ilusión inalcanzable y tentadora del séptimo arte. Pero según Bazin los realizadores pueden explotar esta relación especial que el cine tiene con la realidad y de este modo acercarnos más a su propósito esencial.

En uno de los primeros abordajes teóricos del cine, "París, capital del siglo XIX", Walter Benjamin definió el cine como "la manifestación de todas las formas de visualización de los tiempos y de los ritmos prefigurados por las máquinas modernas, de forma tal que todos los problemas del arte contemporáneo encuentran sólo en el ámbito del cine su formulación definitiva" (Benjamín, 1989:43)

En este sentido el cine expresa -por su naturaleza técnica y productiva- la experiencia de la discontinuidad que las "máquinas modernas" introducen en cada aspecto de la vida cotidiana. Para comprender esta afirmación es necesario tener presentes las mutaciones que la técnica - a fines del siglo pasado y en los primeros decenios del 1900 - imponía a la relación del hombre con la naturaleza y a su misma fisiología.

La ciudad también sufre una transformación. En la metrópolis de fines de 1800 , el universo perceptivo es embestido por una serie de señales, no asimilables para la experiencia tradicional. La discontinuidad se convierte en modo de ser, de ver, de ubicarse en relación con el otro. La experiencia se configura, en términos generales, como un montaje de lo diferente. Su significado es siempre reflejo, de segundo grado, y de alguna forma se agrega artificialmente a la serie sin conexión de las percepciones. 
Siguiendo el pensamiento de Debord, el espectáculo, y el cine como parte integrante de él, se origina en la pérdida de la unidad del mundo y la expansión del espectáculo moderno expresa la totalidad de esta pérdida. En la actualidad muchas películas producidas en Hollywood son un modelo de la función catártica y especular del cine actual.

Como sus antecesoras de los años '70, las nuevas películas catastrofistas llegan en mitad de una crisis económica y política mundial. La guerra de Irak, comparable en ciertos aspectos a la de Vietnam, que servía de telón de fondo a filmes como Aeropuerto, La aventura del Poseidón o Apocalipsis now, es el escenario de hoy. La caída de las Torres Gemelas y el atentado del 11 de marzo en Madrid, han elevado el proceso abierto por el terrorismo internacional en los '70, que reflejaran películas como Domingo Negro, Victoria en Entebbe, entre otras.

Es decir, pareciera que este nuevo milenio reúne las condiciones obvias de una crisis mundial, capaz de direccionar un cine que canaliza los miedos apocalípticos, reconvirtiéndolos en fuente de ingresos a gran escala.

"La película-catástrofe no puede considerarse exclusivamente como un recurso comercial. Al acumular unos estereotipos de cataclismos, las películascatástrofe han reflejado la crisis de la conciencia colectiva (la paranoia) de los estadounidenses en un momento en que sus más firmes convicciones se estaban diluyendo por razones históricas." (Ramonet, 2000:76)

La acción de estos filmes se articula siempre en torno a temas arquetípicos, de resonancias bíblicas y mitológicas a la vez que reflejan miedos ancestrales, estructuras de pensamiento mágicas y resabios apocalípticos clásicos. Fragmentos de los mitos más diversos, de épocas remotas, de las costumbres más exóticas, pueden resucitar en la luz del proyector.

La paradoja es que las imágenes de una auténtica catástrofe, emitidas por televisión, poseen un realismo que compite de lejos con el cinematográfico, reduciendo este último a su naturaleza meramente anecdótica, desprovista de verdad. Llegará el día en que veremos las escenas apocalípticas de films como "El día después de mañana" con la misma sonrisa cómplice con la que hoy se ve TV.

Un efecto secundario es cómo la industria cinematográfica ha contagiado a la industria informativa de su necesidad de espectáculo, obligándola a competir con el cine, situándola muy por encima de cualquier consideración ética o informativa. En este sentido el cine incorpora integralmente la mirada del flâneur (esa contracara del poeta y del intelectual en la modernidad tardía que no se resigna a la experiencia pasiva del hombre de la multitud) baudeleriano.

Con su misma técnica, el cine trata de montar una unidad de significado en el flujo incesante y discontinuo de las tomas. Por un lado éste refleja la fugacidad incesante de la experiencia visual, por el otro trata con todos sus medios de encontrar un remedio a ello y de extraer un sentido a partir del rápido flujo de las impresiones.

Inclusive la técnica de la actuación parece reflejar en el cine la descomposición en fragmentos de la experiencia. El actor teatral todavía podía identificarse con su personaje y ofrecerlo al público con el aura de lo irrepetible: su aparición estaba ligada al momento mismo de la interpretación y a la unicidad de su presencia sobre el escenario. La actuación del actor cinematográfico en cambio está condenada a descomponerse en fragmentos.

La omnipresencia del aparato tecnológico en todas las fases de producción y distribución de un film tiene un gran influjo sobre el modo en el cual vienen producidas y recepcionadas las imágenes. Gracias a la representación cinematográfica el hombre moderno integra la técnica de filmación a la propia cotidianeidad y a su propio mundo habitual, en vez de sufrirla como un poder desconocido e intangible. Entre las funciones sociales del cine, la más importante es la de instituir el equilibrio entre el hombre y el aparato técnico.

El cine es el síntoma expresivo y, a su vez, el antídoto posible frente a la distracción dispersa que se produce en el seno de la experiencia moderna. Con las técnicas del primer plano, de la cámara lenta, de la aceleración, pone en relieve lo que permanece inconsciente en la percepción habitual. De tal forma nos revela justamente un inconsciente óptico, dilatando y dividiendo incluso el más simple de los gestos y así hacerlo presente. El gesto es el verdadero valor diferencial que da lugar al cine de autor, que lo arranca de la recepción distraída del cine espectacular.

Se puede sostener que el cine actúa como una pura válvula de escape, como una inmunización fisiológica contra el imaginario de la modernidad, en vez de integrarlo y de reflejarlo, este cine nos acostumbra a ello. De tal forma permite aceptar con alegría de corazón la brutalidad y la violencia. Walter Benjamin no previó la decadencia del cine de autor y la expansión generalizada del cine comercial. En vez de exhibir la novedad distanciada de las nuevas técnicas de representación, el cine comercial volvió a proponer en gran escala formas arcaicas de fascina-ción. Esta posibilidad está ya presente desde los inicios de la historia del cine. Los primeros escritos de reflexión teórica sobre el nuevo arte subrayan su fidelidad mimética al objeto reproducido, sea su capacidad de someter la realidad a fantasmagóricas metamorfosis: es decir dos características que recuerdan la práctica primitiva de la magia. Quizás por primera vez, gracias al cine, la historia y el pasado se transmutan tan radical e integralmente en espectáculo. De este carácter fascinador debe desenredarse el cine auténticamente expresivo, elaborando formas de representación que sepan interrumpir el hechizo de la identificación.

Cuando los primeros teóricos del cine escribieron sus ensayos, la sociedad del espectáculo aún no se 
había desplegado en toda su potencia. En las últimas décadas ésta ha sustancialmente impedido que las potencialidades críticas de la técnica cinematográfica se expresaran en gran escala. De hecho el film espectáculo, llevado a la perfección poco antes de la segunda guerra mundial, presentaba ya una sistemática denegación de los caracteres revolucionarios. En el cine de autor la operación del montaje es percibida por el espectador y tiende a involucrarlo en un trabajo de lectura, de interpretación activa de la imagen. En el cine comercial, el montaje impide la experiencia de la discontinuidad y desactiva su potencial crítico. "Hollywood inventó un arte que descarta el principio de la composición restringida y que no sólo descarta la distancia entre espectador y obra, sino que deliberadamente crea en el espectador la ilusión de estar en el medio de la acción reproducida dentro del espacio ficticio del film", (Dudley, 1992:132).

Si el cine de autor o independiente tiende a exhibir la imagen en cuanto imagen y la apariencia en cuanto apariencia, solicitando la participación crítica del espectador, el cine espectáculo muestra una apariencia como realidad, atenuando hasta el límite de lo posible la diferencia entre ficción y verdad. La afinación del efecto de realidad realizado por la televisión lleva a su culminación la tendencia a la estetización de la experiencia ya presente en el cine: el ámbito de la verdad coincide con el ámbito de lo visible y de la apariencia. De tal modo el espectáculo cinematográfico asume el papel de lo que está en desuso. La comparación con el efecto de verdad de la imagen televisiva debilita el de la imagen cinematográfica y tiende a elevar con más fuerza la conciencia de su artificialidad. Privadas de la ilusión de la simultaneidad, sus imágenes nos muestran siempre los hechos de un pasado cercano o remoto. Al enfrentarse con la televisión, ellas no pueden dejar de exhibir cada vez más su propio desnivel con el presente y descubrir así su naturaleza adulterada y construida. La mutación completa de nuestra percepción -cada vez más acostumbrada al tiempo televisivo- está aún lejos de haberse cumplido, y sin embargo quizás algún día se volverá general la experiencia de lo desusado que hoy nos asalta frente a las obras maestras del cine mudo: quizás se conozca mejor la prehistoria de la humanidad que los primeros treinta años del cine.

Del mismo modo, no se ven más las películas como se veían en la época pre-televisiva donde el consumo de los productos de esta industria se percibían de manera mucho más ingenua, creíble y fascinante. No está dicho que esto sea un fenómeno puramente negativo: en cierto sentido reabre espacios mayores al cine de autor. La ampliada artificialidad que hoy reconocemos a la imagen cinematográfica, por ejemplo, la vuelve particularmente apta para deconstruir los mecanismos de la ficción televisiva. Así, la misma imagen mostrada en la televisión y después reproducida en un film, se extrae y desencarna de su contexto: sometida a una atención vigilante, ella traiciona su naturaleza de ficción. El cine puede elevarse a un nuevo grado de reflexión. En las series televisivas, por ejemplo, la repetición indefinida, la reducción del montaje a una serie de camposcontracampos, la intersección y el reenvío continuo de las mismas situaciones elementales, producen un simulacro que pretende reproducir la mutación infinita y celular de la vida misma. Como en una toma en directo para paladares poco refinados, nacimientos y amores, enfermedades y muertes, se suceden como si acontecieran detrás de la puerta de al lado. Lo que sucede cada día, se repropone indefinidamente, sin interrupción y sin salida, ennoblecido como un destino gracias a la presencia de las estrellas de TV.

\section{Cine funcional, popular y verosímil}

En 1895, cuando nació el cine, nadie podía decir cómo debían ser los films ni cómo debían resolver la tarea de comunicar la realidad. "La formulación gradual de un lenguaje del cine sucedió durante los primeros 20 años de sus existencia. Hacia 1915 la libertad original del arte estaba sumamente restringida, al tiempo que sus poderes de expresión habían crecido de manera exponencial. El cine desbarató su variedad a cambio de una forma estándar y como resultado ganó en elocuencia. Eligió algunas formas de sus infinitas opciones y esas pocas se convirtieron en el 'cine' que se conoce actualmente. El hecho de que casi todos los films tengan un extensión de entre 80 y 120 minutos fue una convención establecida por eso años. Es un parte inseparable de nuestra noción de cine y un producto de la institucionalización del arte" (Dudley, 1992: 211).

A pesar de los cambios sufridos desde sus orígenes, en un reportaje al pensador francés Jaques Derrida, el autor sostiene que "el cine sigue siendo un arte popular, aun si esto es injusto para con aquellos que, productores, realizadores, críticos, lo practican con mucho de refinamiento o experimentación. Sería incluso el único gran arte popular. Y yo, como espectador más vale ávido, permanezco, acampo incluso, del lado de lo popular: el cine es un arte mayor del entretenimiento" 1.

¿Por qué es el cine la más popular de las artes? Para responder a esta pregunta, hay que articular dos análisis. En principio, uno interno del medio cinematográfico que toma en cuenta la inmediatez de las emociones y de las apariciones tal como se imprimen sobre la pantalla y en el espíritu de los espectadores, en su memoria, en sus cuerpos, en su deseo. A continuación, un análisis que tiene que ver con el hecho de que esta técnica espectral de apariciones se haya ligado muy pronto a un mercado mundial de miradas que permite que toda bobina impresionada pueda ser reproducida en miles de copias susceptibles de conmover a millones de espectadores en el mundo entero, y eso de modo casi simultáneo, colectivo; y es que de haber sido el cine una forma de consumo estrictamente individual o incluso doméstica, esto no habría sido posible. Este cruce es inédito, ya que reúne en un tiempo muy corto la inmediatez de las 
apariciones y de las emociones, y una inversión financiera que ningún otro arte puede igualar.

Derrida se ha acercado de varias formas al lenguaje cinematográfico. "En primer lugar, psicoanálisis y cinematografía, son en verdad contemporáneos; numerosos fenómenos ligados con la proyección, con el espectáculo, con la percepción de ese espectáculo, poseen equivalentes psicoanalíticos". Walter Benjamin tomó muy pronto conciencia de esto, y aproximó desde un principio a ambos procesos, el análisis cinematográfico y el psicoanalítico. Incluso la visión y la percepción del detalle en una película están en relación directa con el procedimiento psicoanalítico. La ampliación no sólo agranda, el detalle da acceso a otra escena, una escena heterogénea. La percepción cinematográfica no tiene equivalente, sino que es la única que puede hacer comprender por experiencia lo que es una práctica psicoanalítica: hipnosis, fascinación, identificación, todos estos términos y procedimientos son comunes al cine y al psicoanálisis, y he ahí el signo de un pensar en conjunto. "Por otra parte, una función de cine es apenas un poco más larga que una sesión de análisis. Uno va a hacerse analizar al cine, dejando aparecer y hablar a todos sus espectros", agregó Derrida.

En otro sentido hay en el cine una modalidad del creer absolutamente singular: hace ya un siglo se inventó una experiencia sin precedentes de la creencia. Sería apasionante analizar el régimen del crédito en todas las artes: cómo se cree en una novela, en ciertos momentos de una representación teatral, en lo que está inscripto en la pintura y, por supuesto -algo totalmente diferente- en lo que el cine nos muestra y nos relata. En la pantalla, tenemos que lidiar imágenes, con voz o sin ella, con apariciones en las que el espectador cree, apariciones que a veces idolatra. Ya que la dimensión espectral no es la del viviente ni la del muerto, ni la de la alucinación, ni la de la percepción; la modalidad del creer relacionada con ella debe ser analizada de modo absolutamente original. Esta fenomenología no era posible antes del cinematógrafo pues esta experiencia del creer está ligada a una técnica particular, la del cine, siendo histórica en su totalidad.

Existe, en nuestra idea occidental de la creencia, una desconfianza irreductible hacia la imagen en general, y hacia la imagen filmada en particular. Esto puede interpretarse como una forma de arcaísmo, esta idea de que sólo la percepción, el verbo o la escritura en su presencia real tienen derecho a la creencia, son creíbles. Jamás se ha adaptado este derecho a la posibilidad del testimonio filmado. Inversamente, también se puede decir que esta desconfianza hacia la imagen filmada toma en cuenta la modernidad de la imagen cinematográfica, la reproductibilidad infinita, y el montaje de las representaciones: la síntesis siempre posible que une la creencia a la ilusión. Una imagen, sobre todo en el cine, es siempre pasible de interpretación: el espectro es un enigma, y los fantasmas que desfilan por las imágenes, constituyen misterios. Se puede, se debe creer en ellos, pero esto no tiene valor probatorio.

En este sentido, caminando por la ficción y no ficción y su función social. François Truffaut señaló hace ya unos años que hay personas que aman la fantasía y las hay que la detestan. Algunos de los que detestan la fantasía fingen amar el cine pero, si se les pregunta, se darán cuenta de que aman sobre todo el cine documental. En alguna ocasión, explicó el director francés, las personas aficionadas a los documentales se dignan a desplazarse para visionar la ficción, pero los espectadores se darán cuenta de que su gusto los lleva hacia historias realistas, situadas geográfica, histórica y sociológicamente. "Como por azar, estas historias son a menudo interpretadas por actores corpulentos, tranquilizadores, porque su ego elimina los que la función del actor supondría de ligereza en el espíritu del público. Nadie critica jamás a estos buenos corpulentos, siempre plausibles como el patrón del bar y los taxistas. Los fanáticos de la verosimilitud concentran sus críticas contra los actores delgados, con las mejillas hundidas y la cabellera revuelta, contra los actores bressonianos cuya introversión hace que se expresen como ventrílocuos. Contrariamente a los actores macizos los actores delgaduchos no disimulan sus miedos, ni pueden ocultar cierto titubeo en su voz, no son domadores sino indomables" (Gispert, 1998:123).

Siegfried Kracauer, teórico del cine alemán, entendió que el cine es un verdadero proceso mediador de la historia por ser una mezcla de arte y ciencia. El autor, que cargaba con una tradición liberal, democrática, y a la vez racionalista, explicó que este proceso mediador pone al hombre en su debida relación con la vida. Los espectadores no se someten ni a la tiranía de los hechos, porque siempre se organizan y componen, ni a la tiranía de la imaginación (porque rechazan aquellas organizaciones y composiciones que aducen supremacía sobre los hechos. Esos procesos permiten a los hombres vivir en un mundo real (Andrew, 1992:163)

Basado en las apreciaciones de Andrew, podemos decir que el realizador elige ciertas percepciones en la realidad como materia prima con las cuales habrá de formar un mundo cinematográfico completo y propio. Puede lograr que ese mundo irradie significados mucho más allá de sí mismo, si aprovecha todas las implicaciones de su material transformándolas por medio de códigos poéticos. En los mayores poemas cinematográficos, los espectadores participantes se reúnen en un mundo complejo que transmite un amplio significado.

En este sentido, "el sentido estético del cine se une a una profunda realidad psicológica y satisface nuestro deseo de comprender el mundo y comprendernos entre nosotros en una forma poderosa aunque necesariamente parcial. La estética del cine se basa en esa verdad y esa necesidad sicológicas. Y así el cine es el arte mayor porque cumple esa necesidad mostrándonos el proceso de la transformación del mundo" (Andrew, 1992:250). 
El cine, en una de sus lecturas más reduccionistas, es igual a los films de ficción que se exhiben o se han exhibido "en las mejores salas". Este cine popular ¿Qué códigos de atracción posee? Los críticos de la mítica Cahiers du Cinéma acusan al cine narrativo convencional de apoyar la ideología dominante de una moderna cultura represiva. Aunque la ideología juega su papel en la financiación, distribución, censura y crítica del cine, estos críticos alegan que la misma base de la significación cinemática está corrompida por una mentira que destruye toda posibilidad de sentido. "Esa mentira es el producto de la insistencia de nuestra cultura en la representación de lo real. Se insiste primero en que la realidad es visible, luego en que el instrumento de la cámara puede captarlo". (Andrew, 1992:280)

Billy Wilder, uno de los grandes realizadores del cine norteamericano clásico, retrató en El ocaso de una vida, al cine como industria culpable de esa función tan irracional de generar la peor decadencia de un artista: el olvido. Tal como afirmó André Bazin frente a las grandes finalidades del cine: una función de privilegio que posee este arte es conservar todo lo que vale la pena de ser conservado.

\section{Notas}

${ }^{1}$ Entrevista por Antoine de Baecque y Thierry Jousse. Publicado en Cahiers du Cinéma, n 556, abril 2001. Traducción: Fernando La Valle. Este texto es el resultado de dos entrevistas con Derrida: una fue realizada en París el 10 de julio de 1998 y la otra, el 6 de noviembre de 2000.

\section{Bibliografía}

Allen, Robert; Gomery, Douglas (1995). Teoría y práctica de la historia del cine. Barcelona: Paidós. Benjamin, Walter (1989). París, capital del siglo XIX. Buenos Aires: Taurus.

Dudley, Andrew (1992). Las principales teorías cinematográficas, Madrid: Rialp.

Debord, Guy (1995). La sociedad del espectáculo. Buenos Aires: La marca.

Gispert, Esther (1998). Los cuatrocientos golpes. Barcelona: Ediciones Paidós.

Gubern, Román (1998). Historia del cine. Barcelona: Editorial Lumen.

Ramonet, Ignacio (2000). Las películas-catástrofe norteamericanas. Madrid: Debate.

Sequeiro, Alejandro; Fabiano, Octavio (1997). Dímelo otra vez. Buenos Aires: Planeta. 